\title{
Editorial
}

\section{Parallax: Striving for a More Resilient International Financial Architecture}

\author{
Patrick M. Liedtke \\ The Geneva Association, 53 Route de Malagnou, CH-1208, Geneva, Switzerland. \\ E-mail: secretariat@genevaassociation.org
}

The Geneva Papers (2010) 35, 1-8. doi:10.1057/gpp.2009.40

\section{Working the credit crisis}

Over the past two years, The Geneva Association has been one of the most prolific and engaged producers and disseminators of contributions on the insurance aspects of the credit crisis. Since the end of 2007, we have been working on this issue rigorously, putting a series of special working groups together that have been analysing specific aspects of the crisis with great dedication. As the international banking system and with it large parts of the financial sector fell into a severe crisis that required unprecedented rescue operations on the highest levels, we enticed and sponsored both internal and external research and analysis on the subject from an insurance perspective. We put demanding and often also awkward questions in front of expert partners and audiences involving not only insurance professionals but also regulators, supervisors, academics, researchers, politicians, shareholders, analysts, rating agencies and other financial specialists. But we also helped find answers through joint discussions and the setup of special projects. Central themes and specific aspects of the crisis became part of our seminars and conferences. We created a dedicated repository of information on our website that would group not only original Geneva Association production, but also some relevant external contributions on the insurance dimension of the credit crisis.

Most recently, The Geneva Association published Anatomy of the Credit Crisis: Insurance Reader from the Geneva Association as part of our Geneva Report Series $\left(\mathrm{n}^{\mathrm{O}}\right.$ 3, published in November 2009 and freely available from our website, www.genevaassociation.org) - yet another reaction to the widespread demand for reliable information on an intellectual appreciation of the insurance sector's involvement in the credit crisis. This issue of The Geneva Papers on Risk and Insurance-Issues and Practice carries a special section also dedicated to the credit crisis and insurance. It is not the only section and complemented by two further, albeit shorter, parts (described in more detail at the end of this editorial): one dealing with strategic issues in insurance and the other presenting the three papers that our joint annual Geneva Association/International Insurance Society (IIS) research award programme produced as winners for 2009 . We are delighted that this programme met with such interest and turned out with such stimulating papers. 
Before introducing the content of this issue, let us point out some important elements that should be taken into account in the general debate on insurance and the credit crises.

\section{The insurance parallax}

A parallax is a physical phenomenon that exists when the line of sight of an observer is not aligned with the axis of his movement towards his targeted object. At that point a strange mechanism takes hold, as the observer perceives an apparent displacement (or difference of orientation) of an object viewed along the line of sight. He might at any point believe he has captured a clear and truthful picture of reality (as far as such a thing is philosophically possible at all), while he actually could be the victim of a misperception. When analysing the credit crisis - the way in which it played out, the role of insurance, and especially the reaction it triggered in the larger financial services area-it seems that unfortunately too many of the involved parties, many of them very relevant for the future of the financial services industry and hence our economic performance, are suffering from such a misperception. Their departing location or viewpoint is anything but optimal for the road they want to take and the target they have set. In the following paragraphs, we hope to set right some of the key fallacies and correct a few misleading notions.

\section{This is a general crisis of the financial sector}

Certainly, looking at any macroeconomic indicator that captures financial activities (profits, growth rates, stock prices, interest rates, credit-default swaps (CDS) spreads, return on investment (ROIs), etc., for financials) one has to conclude that this indeed is a general crisis of the financial sector. However, there are fundamental differences in how certain classes of operators were affected. What interests us is, of course, how insurance fared during the past two years. And, much to the surprise of many observers - especially the less informed - it proved remarkably resilient:

(i) There has been no wave of insolvencies in the insurance sector. Government assistance was - even in the few cases where it was requested, very often not to stave off bankruptcy, but to keep solvency margins at a reassuringly high levelrelatively modest. (Prominent cases of large financial conglomerates with insurance operations or labelled as insurers are dealt with below.) The wave of rescue operations that was necessary in the banking sector and which was feared could engulf the insurance sector too, did not materialise.

(ii) The insurance industry has continued to do business in an orderly fashion during the whole period of the crisis. This contrasts heavily with the banking sector where, for example, credit provision was severely curtailed and even interbank lending came to a halt for a short time in some regions, like the European Union, and until massive government and central bank action kicked in. While banks and many other financial institutions did not trust their peers anymore and hence restricted counterparty interaction to a minimum, the insurance industry continued to share risks on a normal level. 
There is no denying that the crisis has been very painful for insurance operators, especially those in life insurance who control huge pools of assets, often on behalf of their clients, but also to satisfy their future liabilities. Losses were in some cases threatening and sparked certain government action and assistance programmes, especially in the U.S., where embedded guarantees and annuity schemes became problematic. However, despite some companies' problems, the insurance system proved remarkably resilient. It should be reassuring to everybody-policy-holders, supervisors, regulators, policy-makers, investors and the industry itself - that the original analysis of our working group based on The Geneva Association's Amsterdam Circle of Chief Economists has stood the test of time: as reported in detail in the Geneva Report $\mathrm{n}^{\mathrm{O}} 3$, Anatomy of the Credit Crisis, the working group concluded in its original internal report - delivered at the end of July 2008, that is before the Lehman disaster and the massive financial losses that the ensuing panic triggered - that the insurance industry would be much more resilient to the credit crisis than the banking sector. As we know, during the worst financial crisis of the last 70 years it not only survived but does so as a sector in solid shape.

\section{"Insurance" companies failed together with banks}

In its most narrow interpretation this is right. Indeed, in October 2008, Yamato Life, a mid-sized life insurer in Japan went bankrupt. AIG, historically referred to as the world's largest insurance company had to be rescued by an enormous injection of public capital and explicit financial guarantees from the U.S. government, making it the poster child for all those who would like to lump insurance together with other, less resilient financial services providers. Two U.S. life insurance companies, Hartford Financial and Lincoln Financial, requested assistance to keep their solvency ratios up. And in the Netherlands, Aegon, one of the most respected European insurance companies, embraced official help. Similarly, important bank assurance institutions like ING and Fortis required direct government intervention. Consequently, to the superficial observer, there are enough examples as to how insurers failed. However, a more detailed and careful analysis is required.

In this respect, it is important to distinguish three different kinds of financial institutions: banks (retail and investment) on the one hand and (traditional) insurance and reinsurance companies on the other, with a third group, large complex financial institutions, falling in between. All of them fared differently during the crisis. Insurers operating in traditional ways have withstood most of the adverse effects. The rather unique case of the failing Yamato Life was not exclusively the result of the credit crisis but, as Finance Minister Shoichi Nakagawa was quoted saying in the Japan Times (11 October 2008): "The insurer has long engaged in risky business, and it was anticipated that the insurer would develop a negative net worth". It would be surprising that during a period of additional stress, the relatively normal and orderly failure of a company in trouble would not take place. On the contrary, it would be bad for the system if the credit crisis had been used to prop up problematic firms already in trouble.

The government help to the two American life insurers is also remarkable - even though a similar case as for the Japanese company could be made as here two shaky (and not failed) companies out of a total of more than 700 companies (340 alone are 
members of the trade body American Council of Life Insurers (ACLI) is hardly a market-wide failure or systemic problem. In addition, as the companies themselves point out, they fully intend to repay the special government loans and - in retrospect - some insurance supervisors have remarked that the capital support was not really necessary.

Nevertheless, some basic but often neglected, or at times talked-down, problem for life insurers raised its head: financial guarantees given during certain economic periods that come to haunt the risk-bearer when the financial conditions (suddenly) change. The history of life insurance is littered with these cases. Indeed, it is not only a company obligation, but one of the key tasks of insurance supervisors to ascertain that the operating companies that often act as guardians of their policy-holders' funds keep their promises. And where they assume outright financial risk putting their own capital in play, so as to cover future liabilities vis-à-vis their clients, they have to do so in a responsible and sustainable manner. So, to the question: did the life insurance sector in any country fail during the crisis in this respect, the answer is no.

In the wake of the credit crisis, the financial system in general came under huge temporary stress with asset prices suddenly deviating from what most analysis would qualify as a rational price, some markets experiencing severe liquidity constraints, a few even totally seizing up. Unexpectedly, the efficient market hypothesis on which so many models are built upon - and no less important the new International Financial Reporting Standards (IFRS) approach of fair value accounting - showed its central weakness. There was enough uncertainty in the markets, new risk aversion, and political and legal insecurity to push many markets out of the efficient marketoperating zone, not to talk about the irrational and panic behaviour of a larger number of actors than could be normally absorbed by a functioning market. While these extraordinary events were going on, insurance supervisors and some life insurance companies decided to play it safe. There was not enough confidence at the time that short-term price deviations from their long-term development path, which is so central in the planning for life insurance companies and ultimately the variable that determines their operations, would be corrected soon. Hence, capital reinforcement seemed prudent in a few cases. However, at no time was the whole sector in need of substantial financial backing; and certainly not anywhere near the extent that the banking sector which required massive government intervention and rescue. In short: After having gone through the most rigorous real-life stress test of the financial system of the last 70 years, the insurance industry passed the test in good shape and no systemic failure occurred. That should reassure all those who are worried about potential systemic risks in the insurance sector.

\section{Insurance companies should be dealt with like complex financial institutions}

While traditional and conservative-that is "pure-bred"-insurers weathered the adversities well, the same cannot be said of all large complex financial institutions that conduct insurance. The kind of impact observed at a few financial institutions where the core insurance business was complemented through other financial services activities or where insurance is part of other (mainly banking) financial operations, has been ruinous indeed. Most prominently, AIG and Fortis reported massive losses occurring on financial products (mainly CDS and other financial guarantees) and 
banking activities, and ultimately had to be saved through government intervention. Interestingly enough, their insurance operations have repeatedly been reported as sound by the supervisory authorities whose stringent controls of insurance activities apparently led to more careful risk management by the insurance operators within those institutions. In the case of AIG, the ability to service the government debts and the losses incurred by the business unit that conducted financial guarantee business (AIG Financial Products) depends heavily on the soundness and continued operation of the insurance part of the company.

The handful of companies that have suffered most as a consequence of the credit crisis are chiefly those that had special operations as financial guarantors. In this sense, they did not operate as insurance companies but as owners of, and investors in, a different type of business. This is where regulators and supervisors should be alert in the future: insurance companies branching out into risky ventures or other riskier players (such as banks or financial guarantors) moving into insurance, create possible transmission mechanisms previously unnoticed. That means that insurance companies in general should not be dealt with like complex financial institutions. Where a significant amount of other activities inside an insurance conglomerate results in a more heterogeneous risk profile and an increased exposure to highly volatile and/or possibly liquidity-constrained parts of the financial system, in combination with reduced coping abilities during stress, a convincing case for closer scrutiny can be made. However, where insurers stay away from these specific operations and their associated risk classes, or where they only conduct them as very limited parts of their larger and overall diversified activities, there should be no confusion or mix-up with other financial institutions that carry significant risk exposures in these areas.

It is important to remember that insurers have not been submitted to the same systemic issues that many banks are facing today. Nor did they trigger the global financial instability. On the contrary, the insurance industry displayed resilience in the face of adverse market conditions (liquidity squeeze) and was in a position to absorb market volatility, thus acting as a stabilising factor at a time of considerable stress in the global financial system. The credit crisis does not question the business model of insurers, but might question the model of more complex large financial institutions where insurance plays a significant role.

\section{The new financial stability architecture does not need insurance}

Some actors at the institutions that are driving the development of the new international financial stability architecture have wondered whether insurance should be part of the new institutional setup at all. They accept the analysis exposed above and deduct from it that insurance plays no significant role. Consequently, if insurers do not trigger financial instability they need not be involved in any discussions about it. While this might seem plausible at first sight, it is nevertheless wrong. True, a strong case can be made for insurers not posing any significant systemic financial risk in the same way banks do. However, insurance companies have an important role in how any financial crisis might play out. Insurance companies, faced with an ongoing financial crisis, can act as potential multipliers of the crisis, either exerting a stabilising effect or potentially magnifying any problems. This depends on the exact nature of the 
crisis and the mechanisms that will dominate the decision-making processes at the insurance companies, which includes pressure from the relevant outside agencies such as regulators and supervisors. While in this respect more research is clearly neededespecially to use the potential function of insurance companies as circuit breakersone only has to picture what would happen in a severely depressed market if large (life) insurers were pushed to eliminate long-term investments to meet short-term solvency requirements. This particular mechanism could actually be observed in some countries during the 2001/2002 asset crisis, when an overexposure to falling equity markets and certain financial reporting requirements coupled to stringent solvency norms enticed some companies to sell their assets into a falling market, contributing to and accelerating for a certain time an existing downward trend, thus exacerbating an already bad situation. Luckily —or if the insurers' own assessment is believed, due to lessons learned from the past-no such development took place during this crisis.

In as much as any rigorous and comprehensive catastrophe risk management plan requires the integration and cooperation of all concerned parties - and not only those that pose the original risk! - insurers need to be part of ongoing discussions about the international financial stability framework and any plans that define the operations of the financial markets where they play such an important role. On the investment side alone, insurers manage something in the region of 11 per cent of world assets, not to mention their role in protecting other parties' assets too. It would not only be extremely short-sighted to exclude the knowledge that insurers have in managing financial risk and especially tail risk - an understanding so much in demand precisely when events move into the tail of the probability distribution. It would also be counterproductive to the stability of the system if one of the potential sources of re-stabilisation - or an element that if mismanaged during a crisis could multiply negative effects - were not consulted properly on all aspects of the new financial architecture. The new financial stability architecture needs an adequate insurance participation.

There is no doubt that a deeper and more nuanced understanding about the credit crisis and the role that insurance and insurance companies play and have played is required. Most observers agree that the performance of our financial system and its ability to cope with adverse situations and spontaneous stress can be considerably improved. Many solutions will find their way in exactly the area that generated the problems in the first place. However, as good risk management dictates, a thorough analysis of the larger setting is needed and the inclusion of competency should happen where it occurs. The resilience of the future financial architecture depends not only on the emergence of destabilising factors, but also their development in the markets. As insurance plays a key role for the functioning of the financial markets, its possible contribution - good and bad - needs to be further scrutinised. The Geneva Association has been working on this issue intensively and will continue to do so. At the same time, it encourages any third party to share its views and contribute to a wider discussion. The Geneva Papers on Risk and Insurance - Issues and Practice play a central role in this endeavour and we hope to stimulate more original output that could be published in future issues. The function of The Geneva Papers on Risk and Insurance - Issues and Practice is to assist in the evolution of such a debate and to serve as a rigorous forum to its participants, the aim we had in mind as we edited this volume. 
The following pages offer nine contributions from a wide spectrum on the role of insurance in the economy by large. This volume starts with four articles dealing with the credit crisis, its consequences on insurance, risk management and supervision policies. The first one, by Martin Eling and Hato Schmeiser, on Insurance and the Credit Crisis: Impact and Ten Consequences for Risk Management and Supervision, details specific aspects of agency and portfolio theory, a concept for a controlled runoff for insolvent insurers, new principles in stress testing, improved communication aspects, market discipline and accountability, as well as embedding the current practitioners' discussion in the recent academic literature with regard to the regulation of financial conglomerates. The second article on Insurance Regulation and the Global Financial Crisis: A Problem of Low Probability Events by Christopher O'Brien, sees probabilistic approaches and stress tests being considered and analysed as methods for regulators to set the minimum solvency margin for insurers in the light of the global financial crisis; probabilistic approaches are viewed as potentially not robust enough and the conclusion is that regulators may find it beneficial to focus on the use of stress tests, although there are lessons to be learned from the global financial crisis about the design and use of such tests. The following paper On the Impact of the Financial crisis on the Dividend Policy of the European Insurance Industry, by Sebastian Reddemann, Tobias Basse and Johann-Matthias Graf von der Schulenburg, examines the dividend policy of European, and specifically German insurers using VECM techniques; the basic argument being that, without any empirical evidence, dividends actually did matter in the past and that insurers may reduce or even omit dividend payments if needed. The last article of this section entitled Lessons Learned from the Financial Crisis for Risk Management: Contrasting Developments in Insurance and Banking, by Axel Lehman and Daniel Hofmann analyses implications for risk management in insurance arising from the current financial crisis; the author discusses the root causes of the current financial crisis with a particular focus on risk management and incentives.

The following section investigates the advantages to setting up a global solvency standard, especially in the light of the current economic crisis, and investigates the impact of the upcoming Solvency II guidelines on the risk/return tradeoff for life insurance companies. Nikolaus von Bomhard, the author of the first article on The Advantages of a Global Solvency Standard, states that there is a need for a global solvency standard, as risk-taking by global insurance and reinsurance companies operates internationally. It would enable companies to reduce their resources and would make local regulatory capital requirements comparable, thus further paving the way for a level playing field among insurers.

Through the use of the Dutch regulatory framework (FTK) as an example, the huge impact of the elements of Solvency II (balance sheet approach, market valuation, etc.) on capital requirements is demonstrated in the second article on Market Consistent ALM for Life Insurers-Steps Toward Solvency II, by David van Bragt, Hens Steehouwer and Bart Waalwijk. It is shown that by reducing the short-term risk (as measured by the required capital), the long-term expected returns may also decrease.

The third section is devoted to the three IIS award-winning papers. Thomas BerryStölzle, who wrote the first award-winning paper on Successful Business Strategies for Insurers Entering and Growing in Emerging Markets, evaluates the impact of several 
strategies on insurer performance in emerging markets. The main findings suggest that overall, successful business strategies for insurers entering or growing in emerging markets involve a high growth rate, increased size and more emphasis on life insurance. The second paper, presented by W. Jean Kwon, on An Analysis of Organisational, Market and Socio-cultural Factors Affecting the Supply of Insurance and Other Financial Services by Microfinance Institutions in Developing Economies, empirically examines the impact of organisational, market and socio-cultural factors on the supply of insurance, lending and savings services by microfinance institutions in developing countries. The third article on The Cost Efficiency of Takaful Insurance Companies, by Hale Abdul Kader, Mike Adams and Philip Hardwick, examines the cost efficiency of non-life Takaful insurance firms operating in 10 Islamic countries, using non-parametric data envelopment analysis to compute cost efficiency scores and a second stage logit transformation regression model to test the influence of corporate characteristics on these efficiencies.

Last but not least, we are indebted to all the authors who contributed to this volume and we express our deepest gratitude to them. Let us now hope that you will have as much pleasure in reading these articles as we have had in editing this issue of The Geneva Papers on Risk and Insurance-Issues and Practice. 